\title{
EDIÇÃO CRÍTICA DOS TEXTOS POLITESTEMUNHAIS DO CADERNO SEM CAPA 2
}

\author{
Cássia Aparecida Oliveira da Silva ${ }^{1}$; Patrício Nunes Barreiros ${ }^{2}$ \\ 1. Bolsista PROBIC/UEFS, Graduando em Letras Vernáculas, Universidade Estadual de Feira de Santana, e-mail: \\ cassiaoliveira1618@gmail.com \\ 2. Orientador, Departamento de nome, Universidade Estadual de Feira de Santana, e-mail: patricio@uefs.br
}

PALAVRAS-CHAVE: Caderno sem capa 2; Edição crítica; Eulálio Motta.

\section{INTRODUÇÃO}

O presente trabalho está relacionado ao projeto de pesquisa Edição das obras inéditas de Eulálio Motta e tem como objetivo realizar a edição crítica dos textos politestemunhais presentes no Caderno sem capa 2. O escritor baiano Eulálio Motta utilizava cadernos para compor seus textos e deixou, em seu acervo, 15 cadernos com éditas e inéditas. No plano de trabalho desenvolvido durante a bolsa de Iniciação Científica 2015/2016, realizou-se a edição semidiplomática de todos os textos do Caderno sem capa 2. Portanto, a edição crítica parte a edição semidiplomática e da identificação dos textos politestemunhais presente no corpus. Após o levantamento feito no acervo de escritor, foram identificadas 11 textos politestemunhais, apresentando testemunhos manuscritos no Caderno sem capa 2 e impressos no jornal $O$ Serrinhense, datados de 1950 a 1951. O Serrinhense é um jornal da cidade de Serrinha, de propriedade de Bráulio Franco, amigo de Eulálio Motta. No acervo do escritor, consta uma coleção desse jornal, permitindo a sua edição e o cotejamento das variantes para a elaboração da edição crítica. Eulálio Motta foi correspondente do jornal $O$ Serrinhense, assinando uma das colunas do jornal. Os textos são artigos jornalísticos e crônicas que tratam de temas políticos e sociais que estavam em voga na década de 1950. A edição crítica tem por objetivo estabelecer o texto, a partir da análise dos testemunhos, e apresentar um aparato no qual são registradas as variantes.

\section{METODOLOGIA}

A pesquisa fundamentou-se no método filológico da Crítica Textual Moderna (CAMBRAIA,2005; SPAGGIARI; PERUGI, 2004; SPINA, 1994) e nos critérios e princípios de edição das obras de Eulálio Motta estabelecidos por Barreiros (2012; 2015). O corpus da pesquisa constitui-se de 76 textos manuscritos que fazem parte do Caderno sem capa 2 e já se encontram editados. Foram identificados 11 textos politestemunhais publicados no jornal $O$ Serrinhense, datados do ano de 1950 até 1951 e, após a localização dos mesmos, foi realizada a edição crítica, tomando como texto de base aquele que representa a última vontade do autor.

Para esta edição obedeceu-se os seguintes critérios:

$1^{\circ}$ ) Para a ordenação dos textos seguiu-se a cronologia dos mesmos;

$2^{\circ}$ ) Foi escolhido como texto base o último avalizado pelo autor;

$3^{\circ}$ ) Estabeleceu-se um código para identificação dos testemunhos: CSC2 para os textos do caderno e JS para os textos publicados no jornal $O$ Serrinhense;

$3^{\circ}$ ) Para a apresentação do texto crítico:

a) Indica-se o código do testemunho do texto de base;

b) O título do texto em caixa alta; 
c) Os versos são numerados de 5 em 5 e indicados à margem esquerda;

d) Apresenta-se o aparato ao lado do texto crítico, à direita. Indicam-se as variantes em negrito e em tipo menor em relação ao texto crítico, acompanhado do código do testemunho;

e) Utilizaram-se os seguintes operadores para indicar correções, emendas, rasuras, acréscimos, substituições, fragmentos ilegíveis, no aparato:

i) $\langle\uparrow>$ palavra ilegível;

ii) < > segmento autógrafo riscado, apagado;

iii) $[\uparrow]$ acrescentamento na entrelinha superior;

iv) $[\downarrow]$ acrescentamento na entrelinha inferior;

v) $<>[\uparrow]$ substituição por riscado e acrescentamento na entrelinha superior;

vi) $<>[\downarrow]$ substituição por riscado e acrescentamento na entrelinha inferior;

vii) $<>[\rightarrow]$ substituição por riscado e acrescentamento na margem direita;

viii) <>/ \substituição por superposição, na relação <substituído>/substitutol;

ix) ( ) intervenção do editor (acréscimos e informações)

f) Utilizaram-se, no aparato, as seguintes abreviaturas:

i) S.v. (sem virgula);

ii) s.e. (sem exclamação);

iii) s.r. (sem reticências);

iv) s.p. (sem ponto);

v) s.asp. (sem aspas);

g) Manteve-se o uso de maiúscula, conforme o texto base;

h) A pontuação do texto foi mantida conforme apresentada no texto de base;

i) Atualizou-se grafia das palavras conforme norma vigente na língua portuguesa, indicando no aparato a grafia do texto.

\section{RESULTADOS}

A pesquisa permitiu identificar os textos politestemunhais e elaborar a edição crítica das 11 poesias do escritor Eulálio Motta. A partir da lista dos textos contidos no Caderno sem capa 2, empreendeu-se uma densa pesquisa no acervo do escritor para a localização dos testemunhos e definição dos textos politestemunhais.

Após a identificação dos testemunhos, foi realizada a edição semidiplimática dos textos e, em seguida, o cotejamento das variantes para proceder o estabelecimento do texto crítico e compor o aparato. Observou-se que as alterações predominantes nos textos estão relacionadas com a pontuação. Há grande oscilação entre vírgulas e pontos, reticências e exclamação. Além disso, observou-se também alterações no vocabulário com a intenção de lapidar a métrica dos versos.

Nota-se, portanto, que o caderno é a oficina do escritor, onde ele aprimora o seus textos com o objetivo de publicá-los. Alguns textos manuscritos tiveram versos excluídos em comparação com o texto publicado no jornal. Para a edição dos textos, foi necessário fazer uma descrição física de cada um dos testemunhos, com o objetivo de demonstrar as condições materiais e bibliográficas dos textos.

Sabe-se que a edição crítica de um texto não é definitiva, portanto, o que se apresenta é uma hipótese de edição que pretende contribuir para os estudos de crítica textual e para o conhecimento da obra do escritor baiano Eulálio Motta. Segue abaixo um exemplo da edição crítica de um dos textos: 


\section{Texto crítico com o aparato}

ZEFERINOS...

Para "O Serrinhense"

\section{[Coluna 1]}

Zeferino é vaqueiro e tem

"sete bocas nas costas", como

ele diz. Isto é: tem mulher e

filhos. Ganha duzentos e cinquenta cruzeiros por mês. Três mil cruzeiros por ano! Está

"caçando" outro emprego, ou-

tro meio de vida. Outro "gáio", como ele se expressa.

- O patrão é bom, gosto

muito dele, mais o ganho é cur-

to, dá marmente pra cumê. $\mathrm{E}$

15 o pano? E o remédo? E escola

prus minino qui eu nan quero

qui eles crêsçam cego cuma eu?

Só caçano outro gáio. Quando caba daí, o campo muitos dia

20 fica longe de casa, sáio de manhã e chego de noite. Nan tenho natureza de cumê de manhã cumo os outro vaqueiro,

só quebro o jijum cum café

25 puro. O risurtado é qui tou secano. Levá farinha em alforge pru campo nan dá jeito qui ninguem vae corrê atrás de boi cum arfoge na garupa. Só

30 caçano outro gáio. Assim cuma tá nan tá bom não. Tá

runhe. Quando caba daí, o patrão nan deixa qui eu bote um taco de roça na fazenda e nan

35 deixa qui eu crie uma porca.

Cum taco de roça e uma porca, a muié e os minino ia ajudando. Mais assim cuma tá, no ordenado puro e sêco, nan me

\section{ZFJ bôcas}

ZFM tem mulher e seis filhos...

ZFM Ganha 250,00...

$Z F J$ cincoenta cruzeiros por mez.

ZFM <são> 3.000 cruzeiros...

ZFM emprego ou qualquer [ $\uparrow$ outro]
ZFM cumo os outros vaqueiro. $O$ risurtado é que tou secano...
ZFM Só arranjano outro gáio

ZFM nan deixa eu criá uma porca. ZFM $<E$ assim só ordenado e seco>

ZFM Com uma roça e uma porca

ZFM Mais assim no ordenado... 


\section{CONSIDERAÇÕES FINAIS}

A pesquisa possibilitou a edição de textos politestemunhais (11 textos) do Caderno sem capa 2, tomando como base a documentação do acervo do escritor. Os texto editados foram publicados no jornal $O$ Serrinhense e o Caderno sem capa 2 serviu como oficina, onde o escritor esboçou os seus textos para publicá-los posteriormente no jornal. Eulálio Motta também publicou em outros jornais, mas a identificação dos textos foi feita rapidamente por conta da datação constante nos manuscritos. A comparação entre os manuscritos e os impressos permite observar que Eulálio Motta fez poucas alterações nos textos. A maioria das alterações concentram-se na pontuação, especialmente no uso de vírgulas, reticências e exclamações. A temática dos textos gira em torno de questões políticas, principalmente no que diz respeito às eleições para presidência da república e o papel do Partido da Representação Popular no pleito. Além disso, aprece a figura de Zeferino, personagem evocado por Eulálio Motta para representar os trabalhadores rurais explorados pelos patrões.

\section{REFERÊNCIAS}

BARREIROS, Patrício Nunes. O Pasquineiro da Roça, a hiperedição dos panfletos de Eulálio Motta. Feira de Santana: UEFS Editora, 2015.

BARREIROS, Patrício Nunes. Sonetos de Eulálio Motta. Feira de Santana: UEFS Editora, 2012.

BARREIROS, Patrício Nunes. A oficina do escritor e os projetos editoriais de Eulálio de Miranda Motta. Cadernos do CNLF(CiFEFil), v. 13, p. 1465-1480, 2009.

CAMBRAIA, César Nardelli. Introdução à crítica textual. São Paulo. Martins Fontes, 2005.

SPAGGIARI, Barbara; PERUGI, Maurizio. Fundamentos da crítica textual: história, metodologia, exercícios. Rio de Janeiro: Lucerna, 2004.

SPINA, Segismundo. Introdução à edótica: crítica textual. 2. ed. São Paulo: Ars Poetica/EDUSP, 1994. GRÉSILLON, Almuth. Elementos de crítica genética: ler os manuscritos modernos. Tradução Cristina de Campos Velho Birck et al. Porto Alegre: Editora da UFRGS, 2007. 